\title{
Physicians and communities knowledge and awareness about new vaccines in immunization program: A study to derive lesson for increasing uptake
}

\author{
Lahariya $C^{1}$, Khandekar J1', Vachher AS ${ }^{1}$, Pradhan SK ${ }^{1}$, UG Students Research Group ${ }^{1}$ \\ ${ }^{1}$ Department of Community Medicine, Lady Hardinge Medical College, New Delhi, India
}

\begin{abstract}
Background: The knowledge, attitude of physicians about any interventions has effect on the practices while the perceptions about such intervention by caregivers have impact on the acceptance in community.

Objectives: This study was conducted to assess the knowledge and attitude of physicians and perception of the caregivers about new vaccines, and to identify the solutions to address the knowledge gap, if any.

Materials and methods: A cross sectional study was conducted a major city of India from Sept 2006- Jan 2007. 107 physicians and 298 caregivers were interviewed using a pre-tested semi structured interview schedule. The data so collected was analyzed using chi square test and proportions. P value of less than 0.05 was considered statistically significant.

Results: It was found that only $3 / 5^{\text {th }}$ physicians were aware that typhoid vaccination was part of the immunisation program. The knowledge about all the aspects of typhoid was poor amongst physicians in comparison of other vaccine (Hepatitis B) in the immunisation program. Physicians at private health facilities had poor knowledge than those working at government health facilities. However, majority of the physicians had positive attitude towards typhoid vaccination. All the caregivers had heard about typhoid disease and $39.8 \%$ about the vaccine also. Almost $80 \%$ of them were ready to pay for typhoid vaccination.

Conclusions: The study underlines the need for special efforts to increase the awareness about typhoid vaccination amongst these groups to increase the uptake of the vaccine.
\end{abstract}

Key words: Child Health; Hepatitis B, India, Newer vaccines, Typhoid

\begin{abstract}
$\mathrm{A}$ number of vaccines have become available in the last two decades, globally. However, these vaccines have also become part of the immunization programs in many developed nations. The developing countries have poor record in the introduction of these newer vaccines. India, like many developing nations had not introduced any vaccine until 2002 when hepatitis B vaccination was introduced as pilot phase in 33 districts and 14 cities in India ${ }^{1}$ and the State of Delhi was one of the pilot areas. Later in 2004, Delhi became only state in India to have introduced typhoid vaccination in routine immunisation for 2- 5 year old children ${ }^{2}$. However, it was found that coverage with these vaccines was reported to be low in comparison to other vaccines given at the same age group. It has been reported by a number of studies that the knowledge and attitude of physicians have major impact on the coverage with the health interventions ${ }^{3}$. Similarly on the demand side is affected by the awareness amongst caregivers ${ }^{4,5}$.
\end{abstract}

Therefore, the present study was planned to assess the knowledge and attitude of physicians towards hepatitis $\mathrm{B}$ and typhoid vaccines and vaccination program in the State, to assess the knowledge and awareness of the parents and caregivers towards the newer vaccine being part of the routine immunization program in Delhi and to derive lesson on how to reduce the knowledge gap, if any.

Materials and methods

Study design

A cross sectional study conducted between September 2006 to January 2007 in Delhi State of India.

Correspondence

Dr. Chandrakant Lahariya

Safdarjang Enclave

New Delhi, (India)

E-mail: c.lahariya@gmail.com 
Study subjects

The physicians and caregivers were the study subjects. The physicians selected for this study were from three groups:

Group 1: Medical Officers (MOs) at Government health facilities (GHF) (working in the government dispensaries, maternal and child health centres and central government health services clinics). This group was selected as these two vaccines were being delivered through government program.

Group 2: Physicians at Private Health facilities (the qualified allopathic practitioners who were providing immunisation services in at their private clinics). This group was selected as considering the Delhi having approximately $93 \%$ population as urban and a large proportion of immunization is delivered by private service providers and;

Group 3: Faculty members or the residents of the Community Medicine and Paediatrics or departments of the Medical Institutions (MI) in Delhi as these institutions are the places where not only the physicians are trained but a number of immunization clinics are run at different hospital and outside facilities.

\section{Sample size}

A sample size of minimum 30 physicians in each group was planned. Another sample of minimum 210 exit interviews with caregivers was considered to get a confidence limit of $95 \%$ and $5 \%$ acceptable error ${ }^{6}$.

\section{Study area}

Delhi is the capital of India with a total population of approximately 13.8 million as per 2001 population? The State has $93 \%$ population living in urban area with literacy rate of $85 \%$. The infant mortality of Delhi is $13 / 1000$ live births and the proportion of fully immunized infants is $63 \%{ }^{8}$. This is the first and the only state in India, where typhoid vaccination has become the part of routine immunisation. The state has been administratively divided into seventy assembly areas ${ }^{7}$. The study was so planned to select at least one health facility from the each 70 assembly areas to get the desired sample.

\section{The data collection}

It was planned that prominent government health facilities, where immunisation services are provided, will be identified from approximately 35 assembly areas and one private health clinic each from rest of the assemblies. A list of health facilities to be included in this study was prepared before the data collection was started. A total of 28 government health facilities were identified in equal number of assemblies. Another 30 private health facilities were identified from 26 assemblies. Five medical institutions were in 4 different assembly areas. The rest of the assembly areas (12 in total) were not covered as either no immunization facility could be identified from those assemblies or due to some other logistic reason. The data collection team constituted of authors of this paper and a group of 12 students, who trained for a day to familiarize them with the study questionnaire and to make them well verse about the interview techniques. A pre tested semi structured interview schedule was prepared for the physicians. One of the members of data collection team visited the health facility during the clinic/health facility working hours. The physicians present and involved in the immunisation activities were contacted. After their informed consents to participate in the study, they were given a pre-tested interview schedule to fill up and returned on the same visit. It was checked, on the spot, for the completeness by the investigators once the physicians had returned the interview schedule.

The questionnaire for the exit interview was pretested for the inter rater reliability before the actual data collection for the study. The exit interviews of the parents, who had a child aged 2-5 years, were also conducted from these health facilities, where the physicians were interviewed. However, it was not necessary that the child in the specified age group was brought to health facility that day. If the parent/care giver reported that they had a child in the specified age group, they were asked some questions about the typhoid fever and vaccination. Minimum 3 and maximum 5 such subjects were interviewed from each health facility after informed consent. It was pre-decided to interview at least 10 caregivers from each of the medical institutions. The data so collected was entered into the computer and was analysed by using STATA v9.0. The proportions and chi square test were used wherever appropriate. A p value of $<0.05$ was considered statistically significant.

\section{Results}

A total of 107 physicians and 298 care givers were interviewed for this study. Two physicians and 8 caregivers refused to participate for various reasons. (Acceptance rate $98.1 \%$ and $97.4 \%$ for physicians and caregivers respectively). Amongst 107 physicians, 34 were medical officers at GHF (Group 1), 35 physicians at PHF (Group 2) and 38 resident doctors or faculty members at medical institutions (Group 3). 126 exit interviews were conducted at government health facilities, 108 at the private clinics and rest from the medical institutions to make a total of 298.

The information the Hepatitis B vaccine was collected to provide the control for typhoid vaccination. The 
knowledge amongst physicians about hepatitis B vaccine and vaccination was higher than what they knew about typhoid (Table 1). Only 60.7\% (65/107) physicians were aware that typhoid vaccination is part of the UIP in comparison of $86.9 \%$ (93/107), who knew the same about Hep B vaccination (Chi square test= $18.96 ; \mathrm{df}=1 ; \mathrm{p}$ value $<0.001$ ). The knowledge about all aspect of typhoid vaccination was poor amongst private practitioners in comparison to the physicians at GHF. Typhoid vaccine is a Vi polysaccharide vaccine was known to less than half of the physicians. The number of doses and correct age of administration was known to $3 / 5^{\text {th }}$ of the physicians only. The medical officers at government health facilities had higher knowledge than the private practitioners and physicians at the medical institutions.

The only thing correctly answered by almost all the physicians was the dose of the typhoid and hepB vaccines. Almost $90 \%$ physicians believed that typhoid is common amongst people aged more than 15 years (table 1).

Sixty nine percent (64/92) physicians believed that Delhi had sufficient burden of typhoid disease to introduce vaccine in immunization program. However, this proportion was smaller for group 2 of physicians in this study. 56 physicians supported the idea of its introduction in UIP while 26 did not feel any need. Almost one fourth did not have any opinion about typhoid vaccination. The majority of the physician $(67 / 82)$ thought the vaccine to be safe and effective. It was noticed that private practitioners had more negative attitude towards typhoid vaccination than those who were working in GHF or MIs (table 2). The major source of knowledge about the ongoing typhoid vaccination in Delhi, amongst the physicians interviewed through was after attending immunization clinics or from newspaper advertisement by the government. Physicians in the any group did not report any training being given prior or after the introduction of typhoid vaccine in the State.

All caregivers had heard about the typhoid (motijhara in local language Hindi) but only $39.8 \%$ were aware that a vaccine is available for the prevention from typhoid. $45.6 \%$ caregivers said that disease mainly affect children. Less than one third $(29.2 \%)$ caregivers were aware that this vaccine is part of the routine immunisation for children aged 2-5 years in Delhi (table 3 ). In a number of cases (actual data not collected), the child had been given the typhoid vaccine on the day of interview but the caregiver was not aware what vaccine the child had actually received. The caregivers attending private health facilities had more positive attitude towards typhoid immunisation.

On asking whether they would vaccinate their child if typhoid vaccination is offered, $88 \%$ answered affirmatively. Of all these caregivers, 251out of 264 were ready to pay for the vaccination. Only thirteen said that they would vaccinate their child only if the vaccine is offered for free. Every 3 of the 5 caregivers were ready to pay up to Indian Rupees 50 for the vaccine, while $12 \%$ of the respondents were ready to pay even more than Indian Rupees 200 for the vaccination. All but one caregiver attending PHF were ready for vaccination either free or at any payment. The rest of the people, who were not keen for the vaccination, were attending either government health facilities or medical institutions (table 4).

Table 1: Knowledge of the physicians about newer vaccines in Delhi

\begin{tabular}{|c|c|c|c|c|c|c|c|c|c|}
\hline & \multicolumn{4}{|c|}{ Typhoid } & \multicolumn{4}{|c|}{ Hep B } & \multirow[b]{2}{*}{ P Value } \\
\hline Sites where physicians were interviewed & $\begin{array}{l}\text { GHF } \\
(34)\end{array}$ & $\begin{array}{l}\text { PHF } \\
(35)\end{array}$ & $\begin{array}{l}\text { MI } \\
(38)\end{array}$ & $\begin{array}{l}\text { Total } \\
(107)\end{array}$ & $\begin{array}{l}\text { GHF } \\
(34)\end{array}$ & $\begin{array}{l}\text { PHF } \\
(35)\end{array}$ & $\begin{array}{l}\text { MI } \\
(38)\end{array}$ & $\begin{array}{l}\text { Total } \\
(107)\end{array}$ & \\
\hline $\begin{array}{l}\text { The vaccination is part of immunisation } \\
\text { program in Delhi }\end{array}$ & 31 & 11 & 22 & 65 & 34 & 27 & 32 & 93 & $<0.001$ \\
\hline Type of vaccine & 14 & 12 & 20 & 46 & 17 & 24 & 29 & 70 & 0.002 \\
\hline Route of administration & 19 & 26 & 34 & 79 & 32 & 33 & 36 & 101 & $<0.001$ \\
\hline No. of doses required & 32 & 17 & 13 & 62 & 30 & 32 & 38 & 100 & $<0.001$ \\
\hline Age at administration & 29 & 14 & 24 & 67 & 23 & 31 & 36 & 90 & $<0.001$ \\
\hline Cost of single dose & 04 & 21 & 12 & 37 & 20 & 17 & 23 & 60 & $0.076(\mathrm{NS})$ \\
\hline Quantity in single dose & 34 & 33 & 38 & 105 & 34 & 31 & 35 & 100 & $0.089(\mathrm{NS})$ \\
\hline Booster is ever needed & 10 & 25 & 30 & 65 & 21 & 30 & 33 & 84 & 0.005 \\
\hline \multicolumn{10}{|l|}{ Typhoid is common in which age group } \\
\hline$<5$ years & 04 & 14 & 17 & 35 & & & & & \\
\hline 5-15 years & 21 & 28 & 26 & 75 & & & & & \\
\hline$>15$ years & 29 & 29 & 35 & 93 & & & & & \\
\hline
\end{tabular}

Note: $\mathrm{GHF}=$ Government Health Facilities; $\mathrm{PHF}=$ Private Health Facilities; $\mathrm{MI}=$ Medical Institutions 
Table 2: Physicians attitude towards typhoid vaccination

\begin{tabular}{|c|c|c|c|c|}
\hline & The physicians who believed that: & Yes & No & P value \\
\hline \multirow[t]{4}{*}{1.} & Delhi has sufficient disease burden & & & \\
\hline & GHF & 22 & 04 & \multirow{3}{*}{$\begin{array}{l}\text { Chi }=13.30 ; \mathrm{df}=2 ; \\
\mathrm{p}=0.001\end{array}$} \\
\hline & PHF & 14 & 17 & \\
\hline & MI & 28 & 07 & \\
\hline \multirow[t]{4}{*}{2.} & Vaccine should be included in UIP & & & \\
\hline & $\mathrm{GHF}$ & 21 & 05 & \multirow{3}{*}{$\begin{array}{l}\text { Chi=15.68; } \mathrm{df}=2 ; \mathrm{p}= \\
<0.001\end{array}$} \\
\hline & PHF & 10 & 16 & \\
\hline & MI & 25 & 05 & \\
\hline \multirow[t]{4}{*}{3.} & Vaccine is safe and effective & & & \\
\hline & GHF & 17 & 02 & \multirow{3}{*}{$\begin{array}{l}\text { Chi=3.04; } \mathrm{df}=2 ; \\
\mathrm{p}=0.219\end{array}$} \\
\hline & PHF & 26 & 04 & \\
\hline & MI & 24 & 09 & \\
\hline
\end{tabular}

Note: Those who had responded as don't know were not included in the final analysis.

Table 3: Knowledge and attitude of the caregivers about typhoid vaccination

\begin{tabular}{|l|l|c|c|c|c|c|c|}
\hline & & $\begin{array}{c}\text { GHF } \\
(\mathbf{n 1 = 1 2 6})\end{array}$ & $\begin{array}{c}\text { PHF } \\
(\mathbf{n 2 = 1 0 8})\end{array}$ & $\begin{array}{c}\text { MI } \\
(\mathbf{n 3}=\mathbf{6 4})\end{array}$ & N=298 & Percentages & P value \\
\hline 1. & $\begin{array}{l}\text { Caregiver who had heard about } \\
\text { typhoid (motijhara) disease }\end{array}$ & 126 & 108 & 64 & 298 & 100.0 & NA \\
\hline 2. & $\begin{array}{l}\text { caregiver aware that typhoid may } \\
\text { affect children }\end{array}$ & 29 & 79 & 28 & 136 & 45.6 & $<0.001$ \\
\hline 3. & $\begin{array}{l}\text { caregiver who were aware that } \\
\text { there is a vaccine against typhoid }\end{array}$ & 36 & 64 & 27 & 117 & 39.8 & $<0.001$ \\
\hline 4. & $\begin{array}{l}\text { Caregiver who were aware that } \\
\text { typhoid vaccine is given to a } \\
\text { child aged 2-5 years }\end{array}$ & 17 & 50 & 22 & 089 & 29.2 & $<0.001$ \\
\hline 5. & $\begin{array}{l}\text { If typhoid vaccination is } \\
\text { offered, they will get their child } \\
\text { vaccinated }\end{array}$ & 110 & 98 & 56 & 264 & 88.0 & 0.678 \\
\hline
\end{tabular}

Note: GHF: Government Health facility; PP: Private Health Facility; MI: Medical institutions

Table 4: Amount the caregivers were ready to pay for typhoid vaccination

\begin{tabular}{|l|l|c|c|c|c|}
\hline 1. & $\begin{array}{l}\text { Amount care givers were ready to pay for } \\
\text { typhoid vaccination }\end{array}$ & GHF (97) & PHF(107) & MI (47) & Total (251) \\
\hline 2. & Up to INR 50 & 79 & 38 & 37 & 154 \\
\hline 3. & INR 51-199 & 15 & 43 & 06 & 64 \\
\hline 4. & INR. $>200$ & 03 & 26 & 04 & 33 \\
\hline
\end{tabular}

Note: 13 respondents said that they would get their child vaccinated only if the vaccine is offered free.

$\mathrm{INR}=$ Indian Rupee; INR 50.00= US\$ 1.00

\section{Discussion}

This study provides important information about physician's knowledge and attitude towards typhoid vaccination in Delhi, India. The sample size was selected form the entire city, attempting a representative population both for the physicians and the caregivers. The information about Hepatitis $\mathrm{B}$ vaccination was collected to get a comparator for the typhoid vaccine as it was introduced in the city, 2 years prior to the introduction of typhoid vaccination.

The physicians in all the groups had poor knowledge about typhoid vaccination. The knowledge was even worse amongst private practitioners. The higher knowledge about the hepB vaccination hints that since 
hepB vaccination was going on for a longer period, the information percolated in larger group of physicians. While the introduction of any new vaccine should be followed by the trainings of the physicians and the enhanced efforts for IEC and advocacy efforts in general population, it appears that was not done in Delhi. The physicians who were at the government health facilities had higher knowledge about typhoid vaccination as they were using the vaccine in their health facilities. Had the efforts been at large scale, physicians in different groups would have a higher and equal knowledge about the vaccination. The knowledge about Hepatitis $B$ vaccine was higher as it was being introduced for longer time in Delhi. It appears that either it were the personal efforts of the physicians for getting the knowledge or due course of time, which allowed them to get knowledge about the vaccine.

The studies have outlined that the knowledge about the burden of disease of any vaccine helps physicians to form an opinion about the use of a vaccine $\mathrm{e}^{3,8-13}$. However, a major proportion of physicians were not aware about the burden of typhoid disease in Delhi. The physicians were very positive about the safety and efficacy of the vaccine. In the absence of the sufficient knowledge about the typhoid vaccine, the positive belief about the safety and efficacy of the vaccine reflects, probably, general confidence about the vaccines amongst the physicians. The study points towards the need for the training and intensive IEC and advocacy efforts on new vaccines for the physicians in Delhi. The commonest modes of trainings suggested by these physicians were guest lectures in professional body meetings, Continued Medical Education Programs, Newspaper advertisements and pamphlets etc.

It was probably the presence of the typhoid disease in the community that all caregivers had heard about the typhoid disease. It may be considered as dummy indicator for the presence of typhoid disease in the community. Only $40 \%$ of the caregivers knew that a vaccine against typhoid was available and a proportion of them also knew that it was offered to children aged 2-5 years. However, a reasonable proportion of caregivers, whose children had received typhoid vaccine on the day of interview, did not know what vaccination their child had received (data not in the paper). The most of such children were attending the government health facilities. It reflects that children are given vaccination at the health facilities without paying specific attention to educating or informing parents/caregivers about various vaccinations, related efforts and their advantages. The commonest medium suggested for community awareness generation, by the study subjects, was newspaper advertisement and the Television spots.

The study population had very high acceptance for the typhoid vaccination and almost $90 \%$ being ready to spend money for the vaccination. This is an indication that educating people about the vaccination itself may increase the coverage with newer vaccines.

This is, probably, the first study on the knowledge of the physicians about typhoid vaccination in any community and on the caregiver's willingness to pay for vaccination. in India. Both of these aspects may be important for the broader understanding of the new vaccine introduction in such settings.

The study has limitations that the data on the socio economic background of the caregivers was not collected in this study. The data on this aspect would have given better insight about the determinants of typhoid vaccination. Secondly, the caregivers in this study were selected from the health facilities, who may be better motivated than those who do not bring their children to the immunisation facilities. Therefore, their opinion may significantly differ from the rest people in the community.

\section{Conclusions}

It can be concluded that there is limited knowledge about typhoid vaccination amongst the physicians in Delhi and underscores the urgent need for trainings which need to be followed by the introduction of new vaccines. There should be advocacy and information campaigns for general population to make them aware about the vaccination program. Guest lectures and CME were the preferred modes suggested by physicians for the awareness generation. The efforts for community also needed enhanced and the newspaper advertisements and TV clippings were commonest media suggested. Furthermore, every opportunity of the contacts with caregivers should be utilized for giving health education about all the vaccine.

\section{Acknowledgement}

The authors thank all the medical officers, private practitioners, the faculty member $\&$ the residents in the medical institutions and the caregivers, for agreeing to participate in this study. The study could not have been conducted without the active interest and voluntary support of the 'The UG Student Research Group' at Lady Hardinge Medical College, New Delhi, which helped in the data collection. (Astha Singh, Gulafsha Chodhury, Gurcharanjeet Kaur, Bhawna, Charu Arora were the members of this research group). 


\section{References}

1. Government of India. Multi Year strategic Plan of Universal Immunisation program in India (2005-10). New Delhi: Ministry of Health and Family Welfare; June 2005.p.1-68.

2. Government of Delhi, Health. Economic Survey of Delhi. New Delhi: Government of Delhi; 2007.

3. Martinello RA, Jones L, Topal JE. Correlation between health workers knoledge about influenza vaccine and vaccine receipt. Infection control Hospital Epidemiol. 2003;24:845-7.

4. Nichter M. Vaccination in third world, a consideration of community demand. Social science Med. 1994;41:617-32.

5. Daley MF, Crane LA, Chandramouli V, et al. Influenza among healthy young children: changes in parental attitudes and predictors of immunization during the 2003 to 2004 influenza season. Pediatrics. 2006;117:e268-77.

6. World health Organization. Immunization coverage Cluster survey: reference manual. Geneva: World Health Organization; 2005.p.1129.

7. Census of India office. Registrar General of Census operations [homepage on the internet]. [Accessed on Dec 18, 2007]. Available at: www. censusindia.net
8. Department of Health and Family welfare. Delhi Government of Delhi [homepage on the Internet].[Accessed on Feb 19, 2008]. Available at: http://health.delhigovt.nic.in.

9. International Institute of Populations Sciences [homepage on the Internet]. National Family Health Survey-3, 2006. [accessed on march 2008]. Available at: www.iipsindia.org ;

10. Davis MM, Andreae M, Freed GL. Physicians' early challenges related to the pneumococcal conjugate vaccine. Ambul Pediatr. 2001;1:3025.

11. Davis MM, Ndiaye SM, Freed GL, Kim CS, Clark SJ. Influence of insurance status and vaccine cost on physicians' administration of pneumococcal conjugate vaccine. Pediatrics. 2003;112 :521-6.

12. Haupt RM, Isikci O, Kimble WL, Sotos GL, Fu J. Physicians' knowledge and attitudes about rotavirus gastroenteritis and rotavirus vaccine. Pediatrc Ann. 2006;35:54-61.

13. Daley MF, Liddon N, Crane LA, Beaty BL, Barrow J, Babbel C, et al. A national survey of pediatrician knowledge and attitudes regarding human papillomavirus vaccination. Pediatrc. 2006;118:2280-9. 